\title{
POR ESO YO REGRESO A MI CIUDAD
}

\section{(DISCURSO DE ACEPTACIÓN DEL DOCTORADO HONORIS CAUSA POR PARTE DEL SEÑOR LUIS OSPINA, CINEASTA)}

A un pueblo lo quieres, aunque sólo sea para irte. Un pueblo quiere decir que no estás solo, saber que en la gente, en las plantas, en la tierra hay alguna cosa que es tuya y que cuando no estás se queda esperándote.

Cesare Pavese, La luna y las hogueras

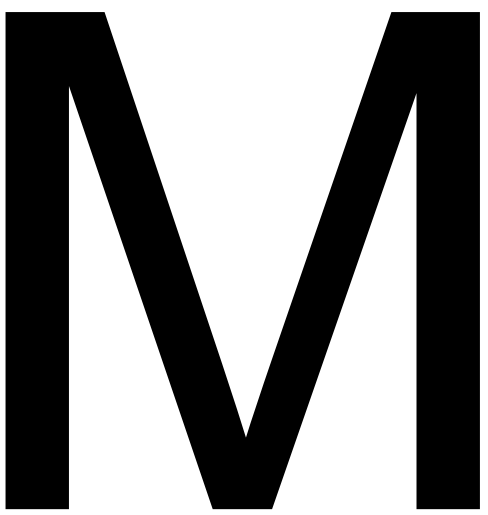

i vinculación con la Universidad del Valle se remonta a mediados de los años 70, cuando Jesús Martín Barbero estaba creando la carrera de comunicación social. Entre los planes futuros de Martín Barbero estaba el cine, razón por la cual nos llamó a Andrés Caicedo y a mí para que lo asesoráramos en la creación del programa de estudios. Los tres soñábamos con que en Cali y, más específicamente, en la Universidad del Valle algún día se hiciera cine. Carlos Mayolo y yo ya habíamos hecho en Cali un par de documentales: Oiga vea, con el apoyo de Ciudad Solar y Cali: de película, con el apoyo de Hernán Nicholls. Con Andrés Caicedo y Ramiro Arbeláez, alumno de historia de Univalle, teníamos el Cine Club de Cali y la revista Ojo al cine. Al abandonar la crítica de cine escrita, Mayolo y yo decidimos llevar la crítica más allá del papel y plasmarla en el cine mismo. Por eso hicimos Agarrando pueblo en 1977, como respuesta a la proliferación de cine de pornomiseria en nuestro medio y en el Tercer Mundo.

El montaje de Agarrando pueblo lo hice en París. Descubrí, como todos los latinoamericanos de esa época, que París era una fiesta. Sí, una fiesta pero una fiesta a la cual no estábamos invitados. Pero París nos pertenecía. Y gracias a la malicia indígena característica del colombiano hasta el cine podía ser gratis. Descubrimos, con mi novia Karen Lamassonne y mis amigos Hernando Guerrero y Carlos Palau, que podíamos reciclar las boletas que todo el mundo desechaba después de entrar. Las recogíamos del piso y las pegábamos con una goma especial y, como por arte de magia, podíamos volver a utilizarlas. Es decir, reciclábamos las boletas para convertirlas en ciclos de cine. Así pude ver lo mejor del cine mundial. Pero algún día las vacaciones tenían que acabar. Aunque era feliz en París, también era indocumentado. Señal de regresar a casa. Pero ¿qué me iba yo a hacer a Cali? Entonces le escribí a mi amigo Luis Fernando Manchola, quien cursaba la carrera de Comunicación Social en Univalle, y le comuniqué mi inquietud. Él me dijo que hablaría con el profesor Fernando Berón, un amigo mutuo, y con el profesor Martín Barbero a ver si había trabajo para mí en la universidad. La respuesta fue afirmativa. 
Entonces a mi regreso me integré a la Universidad del Valle como profesor de cine en la recién creada Facultad de Comunicación Social. Recuerdo que el primer día de clases, un poco en broma y un poco en serio, le dije a mis alumnos: «Muchachos, ustedes están estudiando la carrera del futuro porque en el presente no hay trabajo para ustedes.» Sin embargo en el curso hicimos como media docena de cortos en Súper 8. Era la época del Betamax; veíamos, algunas veces en la universidad y algunas veces en mi casa, cintas de clásicos del cine. Y como lo que más educa es el mal ejemplo, más de uno contrajo lo que Andrés Caicedo llamó la «cinesífilis». Algunos de ellos posteriormente se dedicarían a los medios audiovisuales: Óscar Campo, Liuba Hleap, Claudia Borda, William González, Juan Fernando Franco, Memo Bejarano, Adolfo Cardona y Rodrigo Vidal. Mi carrera en Univalle tan sólo duró un año académico porque la tentación de hacer mi primer largometraje era muy grande, tan grande como mi ingenuidad de tratar de hacer cine en una ciudad donde el cine era una lengua muerta desde la era del mudo. Aunque hubo algunas excepciones y algunas grandes obsesiones. Aparte de los largometrajes El lado oscuro del nevado y Tacones de Pascual Guerrero nada se había hecho en materia de largometrajes desde los años cincuentas. Y como todo el mundo es director de cine hasta que pruebe lo contrario, me lancé a la intrépida empresa de ser el productor, director, montador y coguionista (con Alberto Quiroga) de Pura sangre, una película de vampiros contemporánea inspirada en una leyenda urbana.

A pesar del esfuerzo sobrehumano que significó para mí y mis amigos hacer nuestro primer largometraje, Pura sangre no dio en la vena del público y sólo me dejó un saldo en rojo y la sombra de una deuda. Mi siguiente incursión en el cinematógrafo fue el documental En busca de "María» (1985), que correspondió a un afán que sentíamos el archivista Jorge Nieto y yo por conservar el patrimonio fílmico de nuestro país, rescatando la memoria perdida del primer largometraje rodado en Colombia, María (1921), basado en la inmortal novela de Jorge Isaacs. Aunque María fue un éxito en su momento, después cayó en el más profundo olvido y lamentablemente desapareció, como la mayoría de los primeros largometrajes de ese período.

Al habérseme cerrado todas las puertas del cine tuve que incursionar en un medio audiovisual casi desconocido para mí hasta ese momento: el video. No hay mal que por bien no venga. Paradójicamente el vídeo, y no el cine, se me convirtió en una revelación. Ya no había que tener la fe ciega del cineasta, que como bien sabemos los que tuvimos una educación religiosa, «fe es creer en lo que no se ha revelado». Sino más bien se trataba de creer (y crear) en un nuevo cisma electrónico más inmediato y más barato, ya que no había que violar la película virgen. El vídeo se me convirtió en algo así como el cine sin dolor.

Gracias al vídeo he podido expresarme de una forma más continua y con mayor coherencia, investigando con el documental, en más de una treintena de trabajos, tres temas que siempre me han obsesionado: la ciudad, la memoria y la muerte. Estos temas fueron mi punto de partida para realizar mi primer documental de largometraje en soporte electromagnético: Andrés Caicedo: unos pocos buenos amigos (1986). En este caso me propuse rescatar la memoria de mi amigo, el escritor y crítico Andrés Caicedo. Él, como yo, había sido un muchacho de provincia, enamorado de su ciudad y obsesionado con la muerte y con el olvido. Nueve años después de su muerte prematura decidí hacer un documental con los amigos de Caicedo, que eran también mis amigos, reflexionando sobre su vida, obra y muerte, reconstruyendo a la vez su película inconclusa Angelita y Miguel Angel (1971, codirigida por Carlos Mayolo). Este rescate de la obra de Caicedo lo he continuado también en el campo editorial, al haber coeditado, con Sandro Romero Rey, su obra póstuma en dos libros: la antología de cuentos Destinitos fatales (1984) y la recopilación de crítica cinematográfica Ojo al cine (1999).

En 1988 la Universidad del Valle volvió a aparecer en mi vida. Con la creación del canal regional Telepacífico, la universidad se convirtió en programadora y licitó para un programa documental semanal que se llamaría Rostros y rastros. Pero no había nada qué emitir. Entonces UVTV, la programadora de la universidad, me buscó porque se enteró que yo había acabado el documental Ojo y vista: peligra la vida del artista, una suerte de epílogo a Agarrando pueblo. Busqué a uno de los personajes de Agarrando pueblo, un artista callejero conocido como «El fakir caleño». Sus originales y divertidas reflexiones sobre el cine mismo y sobre su oficio quedaron plasmados en Ojo y vista: peligra la vida del artista, que se escogió como piloto para la serie Rostros y rastros, que se convertiría en el semillero del documental caleño. Posteriormente realicé para este programa otros documentales sobre Cali y sus gentes. Antonio María Valencia: música en cámara, en el cual rescato la memoria del hombre que prácticamente «inventó»la 
cultura en Cali, pues no sólo fundó un conservatorio de música, sino también la primera orquesta sinfónica, la primera escuela de bellas artes, la primera coral y la primera academia de ballet. Este trabajo se editó en la Universidad del Valle y en el montaje trabajó un egresado de Comunicaciones, el futuro director de cine y profesor Antonio Dorado.

El ambiente que se vivía en las instalaciones de UVTV era de una sana competencia. En los corredores me encontraba yo con mis ex alumnos Oscar Campo, Memo Bejarano y Adolfo Cardona, quienes estaban haciendo sus primeros documentales. De alguna manera mis documentales se fueron volviendo un referente para ellos, como si se tratara de la extensión de nuestra antigua relación de profesor y alumno. Ahora sí había trabajo para ellos. Y para otras personas de talento como el camarógrafo Oscar Bernal y el sonidista César Salazar, que fueron mis ojos y mis oídos en casi todos mis trabajos. La universidad me permitió investigar más a fondo sobre la cultura popular caleña y el producto de esta investigación fueron varios documentales: Arte sano cuadra a cuadra, sobre los hippiesartesanos, Fotofijaciones, sobre mi gran amigo y fotógrafo de cabecera Eduardo Carvajal y Adiós a Cali / ¡Ah, diosa Kali!, sobre la destrucción de nuestro patrimonio arquitectónico. Así como la «trilogía de oficios» que llamé Al pie, Al pelo y $A$ la carrera. ¿Por qué escogí a los lustrabotas, a los peluqueros y a los taxistas como tema? Porque ellos desempeñan en la sociedad un papel similar al del documentalista. Ellos, a su manera, también son comunicadores sociales; en el desarrollo de su actividad reciben y transmiten información muy variada de un amplio espectro social. En estos tres oficios, casi siempre, se establece un diálogo muy rico entre el trabajador y el usuario; con ellos no sólo se puede hablar de su trabajo, sino también de política, deporte, moda y de temas actuales como la situación del país y la violencia que nos acosa.

Ante la influencia cada vez mayor del narcotráfico en Cali y mi creciente desencanto con el rumbo que tomaba la ciudad, a instancias de los profesores de Univalle Ramiro Arbeláez y Alejandro Ulloa, emprendí con la historiadora Beatriz Llano un proyecto documental de largo aliento: Cali: ayer, hoy y mañana (1994-5), una serie de diez capítulos monográficos que combinaban material grabado por mí con material de archivo de «Rostros y Rastros». Este trabajo fue como un ajuste de cuentas con mi ciudad, en él que pude plasmar mi relación de amor y odio con Cali, una ciudad que había sufrido tantos cambios que yo ya no la reconocía y en la cual me sentía como un extraño. Cali, que para mí siempre había sido una fuente continua de inspiración, se había convertido ahora en un paraíso perdido que tenía que atrapar antes de que se me escapara de las manos. Al finalizar esta serie abandoné Cali y me fui a Bogotá para realizar, por invitación de mi hermano Sebastián, Soplo de vida, mi segundo largometraje, diez y ocho años después de Pura sangre. Pero esa ya es otra historia.

Mucho ha pasado desde esas primeras clases de cine que di en la Universidad del Valle. El cine ya no es la carrera del futuro. Desde hace cinco años existe en Colombia una Ley de Cine y este año se estrenaron más de diez largometrajes colombianos. El sueño que tuvimos Jesús Martín Barbero, Andrés Caicedo y yo es una realidad del presente. Además de producir los documentales más innovadores de Colombia, la Universidad del Valle ha participado en la producción de dos largometrajes que demostraron que "Caliwood" no ha muerto: El rey de Antonio Dorado y Yo soy otro de Óscar Campo. Con el riesgo de sonar temerario en una universidad en tiempos tan convulsionados, me atrevería a decir esto: me siento orgulloso de haber sido el que tiró la primera piedra.

Uno puede recibir muchos reconocimientos a lo largo de la vida pero no hay ninguno como el que se recibe en la propia tierra y de su propia gente. Por eso regreso a mi ciudad y le agradezco de todo corazón a la Universidad del Valle el haberme otorgado este grado honoris causa y al profesor Ramiro Arbeláez por haber sido el gestor de esta iniciativa. Asimismo quiero agradecer a mi familia, a mis amigos y colaboradores y a las mujeres que me amaron por haberme apoyado durante todos estos años. Sin ellos no sería nadie. 